\title{
SOBRE A INVESTIGAÇÃO SOCIAL EMPÍRICA: CONSIDERAÇÕES INICIAIS BASEADAS NO PENSAMENTO DE Adorno e HorkHEIMER*
}

Flávia Maria Soares Pereira da Silva**

\begin{abstract}
Mas: não estar pronto e acabado e saber que não está é o traço característico daquele pensamento com o qual vale a pena morrer.
\end{abstract}

AdORNO e HorkHEIMER

\section{RESUMO}

O presente artigo tem como objetivo apresentar alguns elementos que permitam refletir sobre o processo de produção do conhecimento e sua relação com a investigação social que se centra na adoção de procedimentos empíricos. Para tanto, a teoria crítica da sociedade - e, com especial ênfase, as idéias defendidas por T. Adorno e M. Horkheimer - constitui a referência básica. Dessa forma, pretende-se evidenciar aspectos que expressem o desenvolvimento da racionalidade, o entrelaçamento entre esclarecimento e mito e as implicações deles decorrentes.

Palavras-chave: conhecimento, investigação social empírica, teoria crítica.

Adorno, no aforismo "Lacunas", afirma que

o conhecimento se dá numa rede onde se entrelaçam prejuízos, intuições, inervações, autocorreções, antecipações e exageros, em poucas palavras, na experiência, que é densa, fundada, mas de modo algum transparente em todos os seus pontos. (1992, p. 69)

\footnotetext{
* Recebido em 7/11/2003 e aprovado em 12/2/2004.

** Professora da Faculdade de Educação da Universidade Federal de Goiás, doutoranda do programa de pós-graduação em Psicologia Social da PUC-SP. E-mail: flaviamsp@uol.com.br
} 
Do conhecimento que é construído dessa maneira, a investigação social empírica parece querer se distanciar. Mais do que isso, a sua legitimidade é questionada - e até mesmo negada - por esse tipo de proposta. Nela, o que vemos é a tentativa de isolar - e, muitas vezes, negar - os interesses e valores de todo aquele que se coloca aberto à experiência de conhecer. De acordo com essa perspectiva, só assim o conhecimento poderia ser alçado à categoria de científico.

$\mathrm{O}$ trajeto, que fez com que essas diferentes formas de compreender o processo de construção do conhecimento fossem sendo elaboradas e estabelecessem-se como referências, é longo. Ele remete à própria história da humanidade e da civilização. Seria pretensão da nossa parte querer retomá-lo em toda a sua complexidade. O que nos propomos, nesse momento, é tentar apresentar alguns aspectos que evidenciem tais diferenças - entre o conhecimento entendido tanto como mediação e manifestação da experiência como resultante de um processo de isolamento dos dados e fenômenos - e as suas implicações, principalmente para a produção da ciência:

Bacon, assim como outros inúmeros pensadores, já afirmava, em 1825, que "a superioridade do homem está no saber, disso não há dúvidas" (ADORNO; HorKHEIMER, 1984, p. 19). E o progresso do saber - no limite, o progresso da racionalidade - funda-se na dissolução dos mitos e no abandono das explicações que neles se baseiam, tornando possível a criação de mecanismos para se lidar com as forças desconhecidas (e, por isso mesmo, temidas), provenientes da natureza. Este, segundo os autores teóricos críticos - em particular, Adorno e Horkheimer -, representava o projeto do esclarecimento: desencantar o mundo através do desenvolvimento da racionalidade e, ao fazê-lo, livrar os homens do medo. Mas tal projeto não se efetivou, e a realidade atesta esse fato. Pelo contrário, o esclarecimento perverteu seus objetivos. Na luta contra a imaginação, contra a mitologia, ele próprio acabou assumindo um caráter mítico.

A procura pela unidade, a eliminação de tudo que remeta à heterogeneidade, a defesa da repetição como critério por meio do qual é possível validar a explicação dos fenômenos e acontecimentos, tudo isso revela o entrelaçamento do esclarecimento com o mito. Adorno e Horkheimer, ao tratarem desse tema, indicam o principal elemento que se apresenta e constitui ambos, esclarecimento e mito: o fato de se originarem do medo. Tal origem traz, como consequiência, a necessidade 
de se diferençar da natureza, duplicando-a e, desse modo, buscar o afastamento daquilo que atemoriza. Afirmam esses autores:

A duplicação da natureza como aparência e essência, ação e força, que torna possível tanto o mito quanto a ciência, provém do medo do homem, cuja expressão se converte em explicação. (1984, p. 29)

Nessa perspectiva, a relação com a natureza - externa e interna e, ainda, a relação dos homens entre si - deve ser compreendida tendo em vista os mecanismos criados no intuito de permitir-lhes enfrentarem a ameaça e o medo. É isso que está na base do processo de formação dos homens, da sociedade, da ciência e da cultura.

Um dos principais compromissos do saber e da racionalidade é favorecer o desenvolvimento de condições de vida que levem os homens a serem mais livres. A técnica seria um dos instrumentos por meio do qual esse compromisso poderia ser cumprido. Contudo, no percurso que levou à tentativa de implantação do projeto do esclarecimento, outros elementos foram emergindo. Ao retomar esse percurso, logo se observa que o esclarecimento, no trajeto de seu desenvolvimento, passou a abrigar em si não só o propósito de libertação e progresso da humanidade. Ele foi (e ainda é) marcado por tendências regressivas, tendências que se revelam, sobretudo, nas relações de dominação que os homens estabelecem entre si. $\mathrm{O}$ aspecto regressivo do esclarecimento também fica patente quando se constata que a técnica, reconhecida como instrumento, como meio, transformou-se na essência do esclarecimento. A ciência moderna, com a sua organização, testemunha esse acontecimento.

No que diz respeito à relação entre saber e técnica, Adorno e Horkheimer são enfáticos, ao afirmarem:

O saber que é poder não conhece nenhuma barreira. [...] Do mesmo modo que está a serviço de todos os fins da economia burguesa na fábrica e no campo de batalha, assim também está à disposição dos empresários, não importa a sua origem. [...] A técnica é a essência desse saber, que não visa conceitos e imagens, nem o prazer do discernimento, mas o método, a utilização do trabalho dos outros, o capital. $(1984$, p. 20)

Tal compreensão ressalta e denuncia a aliança do conhecimento e do progresso tecnológico com o poder. Talvez uma das principais 
contribuições da obra de autores como Adorno e Horkheimer seja representada, justamente, por essa denúncia. Com ela, a face irracional do esclarecimento mostra-se sem véus, sem máscaras. Buscar elucidar as condições que fazem com que os homens, apesar de alcançado o atual estágio de desenvolvimento, submetam-se e defendam situações de vida tão aviltantes: no limite, este era o objetivo que orientou sua obra. Eles buscaram compreender, afinal, "por que a humanidade, em vez de entrar em um estado verdadeiramente humano, está se afundando em uma nova espécie de barbárie" (1984, p.10).

É inegável que o avanço tecnológico não garantiu aos homens a felicidade. Também é inegável que a preocupação - e o investimento com ele relacionado alcançou níveis quase inimagináveis, nos últimos tempos. Isso pode ser reconhecido em várias esferas e em diferentes momentos. Nessa perspectiva, cabe pensar, por exemplo, nas repercussões advindas do fato de a técnica passar a se destacar, ocupando um lugar central no processo de construção do saber.

Com o primado da técnica houve o abandono dos conceitos. Esses últimos - por suporem que "cada coisa só é o que ela é tornando-se aquilo que ela não é" (ADORNo; HorkHEIMER, 1984, p. 29) - já trazem em si a possibilidade da contradição, algo que constitui o pensamento dialético e que é visto com desconfiança, principalmente, pela ciência positiva, ciência que representa uma das expressões máximas do esclarecimento que se converteu em mito.

Vale lembrar que, nas palavras de Adorno e Horkheimer, "para o esclarecimento, aquilo que não se reduz a números e, por fim, ao uno, passa a ser ilusão" (1984, p. 23). Entretanto, a total redução e subordinação do conhecimento aos números é, ela mesma, uma ilusão e já indica a sua mitologização, manifestado não pelo culto às forças naturais (ou sobrenaturais), mas pelo culto extremado à mensuração, à quantificação. Dessa forma, no mundo da calculabilidade e da instrumentalização, o lugar dos deuses é ocupado pela técnica e pelos procedimentos rigorosos que permitem a manipulação, num certo sentido asséptica, dos dados. Reafirmando esse pensamento, os autores citados indicam que "o princípio da imanência, a explicação de todo acontecimento como repetição, que o esclarecimento defende contra a explicação mítica é o princípio do próprio mito" (1984, p. 26).

Submetido a rituais de ordenamento e classificação, o pensamento e a reflexão ficam obstados, ostentando uma aparência de independência, 
de autonomia, em relação aos objetos sob os quais se detêm. O que define o processo de elaboração do saber é o método, a técnica e a aplicabilidade imediata do conhecimento. A investigação social que se fixa nos moldes predominantemente empíricos pode ser considerada uma das principais formas de expressão desse movimento, que tem na defesa da primazia do método sua principal característica.

A aliança entre conhecimento científico e investigação social empírica não se instalou de forma imediata, tampouco se deu de modo abstrato. Pelo contrário, deve-se reconhecer as configurações históricas e culturais que permitiram que esse vínculo se estruturasse. Na perspectiva adotada pelos autores, é fundamental recuperar o caráter constitutivo, dado pela organização da sociedade, pela maneira como as relações e forças econômicas, de produção, articulam-se e recriam-se na realidade, fazendo com que a dominação perpetue e continue mediando os vínculos instituídos pelos homens.

Tendo como referência o estágio alcançado pelas forças produtivas, Adorno afirma ser pertinente considerar a atual sociedade como sendo industrial. ${ }^{1}$ Tal consideração funda-se no seguinte reconhecimento:

Por toda a parte e para além de todas as fronteiras dos sistemas políticos, o trabalho industrial tornou-se o modelo de sociedade. Evolui para uma totalidade, porque modos de procedimentos que se assemelham ao modo industrial necessariamente se expandem, por exigência econômica, também para setores de produção material, para a administração, para a esfera da distribuição e para aquela que se denomina cultura. (AdORNo, 1984, p. 68)

Ainda de acordo com o pensamento de Adorno e Horkheimer, o modelo industrial parece não encontrar barreiras para a sua expansão, afetando e determinando todas as dimensões da vida humana. As relações, em suas mais variadas formas de articulação, são marcadas pela subordinação a mecanismos que promovem a padronização, a homogeneidade e a uniformização. Um exemplo relativo a esse fato pode ser encontrado na crescente fragmentação, além da inclusão a esquemas previamente definidos que caracterizam toda e qualquer produção. $\mathrm{O}$ mundo, sob a égide desses preceitos, manifesta-se como o mundo do sempre-igual, das possibilidades infindas de substituição, subsidiado pelo princípio da troca. "A substitutividade converte-se na fungibilidade universal" (ADORNo; HoRKHEIMER, 1986, p. 25). É assim que o princípio 
da troca revela-se, de forma suprema, como algo indispensável às relações de produção e às relações dos homens entre si. Nesse contexto - permeado por uma racionalidade que promove a inversão entre fins e meios, cujo caráter instrumental invade todas as esferas -, a investigação social empírica encontra terreno fértil para se estabelecer como modelo para a ciência.

Não restam dúvidas de que, nos últimos tempos, essa forma de se processar a investigação dos fenômenos sociais - tendo na empiria a base de sua sustentação - tornou-se um fim em si mesma, procurando sobrepujar-se aos conhecimentos (e às ciências) que não trazem, em sua origem, a exigência - mesmo que implícita - da submissão do pensamento a tais procedimentos. Entretanto, o problema é mais amplo e não reside apenas na obrigatoriedade da adoção desses procedimentos. ${ }^{2}$ O que se tornou problemático, e deve ser destacado, foi o fato de que a investigação social empírica adquiriu um status de disciplina independente. $\mathrm{E}$, o que parece ser mais grave, isso ocorreu em detrimento das outras áreas de conhecimento e de toda e qualquer reflexão que remeta às relações mais amplas, que constituem os fenômenos sociais. A ciência sucumbe ao mito.

Como já mencionado anteriormente, tais fatos não se deram de modo abstrato. Pelo contrário, eles elucidam o movimento relativo às formas de organização da sociedade e do próprio saber científico. Nas palavras de Adorno e Horkheimer:

Que este método se estabelecesse depois como disciplina particular e autônoma no campo da investigação a que se aplica dependeu mais da organização da atividade científica que do caráter específico da sociologia e de seu objeto. (1973, p. 120)

Os princípios orientadores da investigação social empírica assentam-se na constante busca pela objetividade científica e, aliada a ela, a busca pela neutralidade. Tal preocupação - com a objetividade e a neutralidade - acaba por determinar as concepções referentes ao objeto e aos procedimentos a serem adotados no seu estudo. Isso faz ainda com que a investigação seja necessariamente sustentada pelo emprego de instrumentos que permitam a quantificação, pela definição de critérios precisos de verificabilidade e pela utilização de recursos estabelecidos e definidos a priori, os quais devem favorecer o isolamento dos fenômenos a serem estudados. Nada deve escapar ao controle, e é por isso que se 
postula a eliminação de toda e qualquer interferência de aspectos que possam ser considerados subjetivos ou especulativos, que não se refiram aos princípios gerais da investigação empírica. Dessa maneira, é justificado o interesse, cada vez mais freqüente, pelo domínio da técnica e o excessivo apego aos dados, os quais, ao permitirem a manipulação, são entendidos como portadores de um caráter objetivo.

Diante do que foi exposto, pode-se afirmar que, na atividade científica moderna, a subordinação dos objetos aos procedimentos metodológicos de pesquisa é assumida sem nenhum acanhamento. Acredita-se que por meio dessa subordinação é possível garantir a isenção, o isolamento dos valores e os interesses dos pesquisadores. Contudo, aí também se revela o fetiche da técnica, marca da produção no mundo administrado, sua manifestação no campo científico e na configuração, em particular, de uma forma determinada de estruturação da relação sujeito e objeto.

A necessidade de distanciamento diante da natureza e dos objetos em geral já foi anteriormente indicada como pré-requisito fundamental para que a racionalidade e a construção do conhecimento desenvolvamse. Mas, para além desse reconhecimento, a reflexão acerca das implicações e da importância do distanciamento também traz à tona a discussão sobre a relação sujeito e objeto. É nessa perspectiva que parece ser válido pensar nos contornos que ela adquire, tendo em vista a proposta elaborada e defendida pela investigação social empírica. Antes, porém, parece ser conveniente considerar alguns elementos que se referem à compreensão dessa temática, na perspectiva adotada por Adorno e Horkheimer.

A insistência em não assumir um posicionamento conciliador $\mathrm{e}$ harmonioso sempre representou uma característica marcante do pensamento dos teóricos críticos mencionados. Essa postura evidenciouse no entendimento de todo o processo de construção do saber. À recusa ao pensamento conciliador contrapôs-se o reconhecimento, por parte desses autores, da permanente tensão que constitui a relação entre sujeito e objeto. ${ }^{3}$ Por um lado, cabe ressaltar que a defesa da existência da tensão não implica pensar tal relação como se ocorresse entre duas dimensões opostas, dicotômicas e plenamente separadas. Pelo contrário, a tensão já revela o caráter de reciprocidade que permeia tanto a relação como a própria constituição do que aqui denominamos dimensões (sujeito e objeto). Mas, por outro lado, deve-se admitir aquilo que há de verdadeiro 
quando se indica a separação, em particular aquela que se refere à relação entre sujeito e objeto. A esse respeito, Adorno afirma:

A separação entre sujeito e objeto é real e aparente: verdadeira porque no domínio do conhecimento da separação real consegue sempre expressar o cindido da condição humana, algo que surgiu pela força; falsa porque a separação que veio ocorrer não pode ser hipostasiada nem transformada em invariante. (1995, p. 1982)

Portanto, o entendimento e a apresentação da relação entre sujeito e objeto, como se ela ocorresse de forma naturalmente cindida, já indica alguns aspectos importantes da própria articulação e organização da ciência em geral. Esta, ao não considerar o papel determinante do contexto objetivo e das forças sociais na compreensão da relação sujeito e objeto e de todas as relações que remetem ao processo de desenvolvimento da racionalidade, torna-se ideologia. Um olhar que se detém sobre os rumos tomados pela investigação social empírica permite vislumbrar o quanto essa perspectiva expressa tal entrelaçamento - entre ciência e ideologia. Pode-se reconhecer assim que a recusa em analisar os fenômenos e objetos na sua dimensão social, inseridos em uma totalidade, faz com que o conhecimento produzido possa ser apropriado sem resistências, servindo como argamassa que promove e justifica o pleno funcionamento da sociedade administrada e da racionalidade que a constitui e permeia-a.

Há ainda outros aspectos que devem ser salientados e que estão vinculados ao contexto de um mundo administrado, regido pela racionalidade tecnológica e que traz consequiências para o desenvolvimento do saber científico. Um desses aspectos refere-se ao fato de propor-se e exigir, cada vez mais, a elaboração de critérios de ordenamento e classificação. Isso se manifesta de diferentes formas e em vários momentos. O próprio enquadramento das pesquisas em tipologias (pesquisa qualitativa e pesquisa quantitativa, pesquisa pura e aplicada) representa um dos exemplos explícitos da tendência classificatória que explicita, no limite, o compromisso com a padronização. Contudo, esse movimento não é aceito sem questionamentos. Prova disso é que opiniões e posições contrárias a essa proposta estanque e dicotomizada de se compreender a produção científica são emitidas.

Horkheimer e Adorno, ao discutirem a relação entre análise qualitativa e quantitativa, afirmam: 
Os elementos cognitivos que servem de ponte entre os métodos estatísticos e a sua apropriada aplicação a determinados conteúdos são, de um modo geral, de natureza qualitativa. Hoje [...] já se reconhece a necessidade de uma análise qualitativa, não só como integração mas também como elemento constitutivo da investigação social empírica. (1973,p. 125)

Embora a contraposição entre a pesquisa (e a análise) qualitativa e a quantitativa seja questionada por esses autores, eles admitem que por meio dela evidencia-se não só a crescente fragmentação e padronização dos procedimentos envolvidos no desenvolvimento científico, mas também o movimento da história em geral. Nesse sentido, o fato da investigação social empírica e dos métodos a ela associados terem se tornado referência nos estudos das ciências sociais já permitem denunciar o estado de organização da sociedade. Ainda citando Horkheimer e Adorno:

O inflamado debate contra a ampliação dos métodos científiconaturalistas à área apologeticamente denominada do espírito não leva em conta a efetiva "naturalidade" dos objetos das ciências sociais, que lhes é conferida, em grande parte, pela própria sociedade, convertida em segunda natureza e para a qual esses objetos não são, de maneira alguma, determinações espirituais. (1973, p. 126)

Não se trata, portanto, de levantar bandeiras contra a aproximação e aplicação dos métodos das ciências naturais ao estudo dos fenômenos sociais. Tal discurso, ainda que em parte pertinente, limita a crítica ao não evidenciar o processo por meio do qual isso tornou-se possível, processo este que, ao ser considerado, faz com que sejam avistadas as marcas da sociedade na constituição desses fenômenos. Ressalta-se assim que "a possibilidade de aplicação prática à ciência da sociedade depende, substancialmente, das condições da própria sociedade" (1973, p. 129).

Também merece ser considerado, nessa discussão, o lugar ocupado pela teoria em decorrência da primazia atribuída aos procedimentos metodológicos, no processo de produção do conhecimento.

Em seu texto, Notas marginais sobre teoria e práxis, Adorno (1995) salienta que a ênfase e restrição aos dados e às técnicas que permitem a sua mensuração, a acentuada preocupação em produzir-se 
um conhecimento que tivesse, desde o seu princípio, uma utilidade, uma aplicabilidade imediata à realidade, enfim, o enaltecimento da práxis, foi acompanhado pelo sacrifício da teoria. Conhecimento válido passa a ser aquele que se dirige imediatamente ao cotidiano; é o conhecimento aplicável, útil. Nesse contexto, o pensamento perde a sua força, sua resistência, convertendo-se, quando muito, em mais um produto a ser entregue ao mercado. As consequiências desse movimento - não só em relação à teoria, como também em relação à práxis - foram apontadas por Adorno quando asseverou que

a aversão à teoria, característica de nossa época, seu atrofiamento de modo nenhum causal, sua proscrição pela impaciência que pretende transformar o mundo sem interpretá-lo [...] tal aversão à teoria constitui a fragilidade da práxis. (1995, p. 211)

A recusa em assumir essa postura aversiva em relação à teoria não deve, entretanto, conduzir a um outro equívoco que se apresenta na proposta de dissolução das diferenças e, como conseqüência, da oposição existente em relação à práxis. Tais diferenças, segundo Adorno, estão presentes na origem de ambas, e sua manutenção traz um elemento progressivo. Por um lado, é ilusória a idéia da existência do espírito ocorrendo e se desenvolvendo, de forma independente da constituição e intervenção da práxis, do trabalho material. Mas, por outro, postular tal independência já faz com que as desigualdades venham à tona e, assim, afirma-se o caráter progressivo, presente na defesa dessa idéia. Adorno, a esse respeito, sublinha:

O fato de que alguns vivam sem ocupar-se do trabalho material e gozem de seu espírito como Zaratustra de Nietzsche, esse injusto privilégio implica que tal coisa seria possível para todos; ainda mais em um nível das forças produtivas técnicas que permite vislumbrar a dispensa universal do trabalho material [...]. (1973, p. 213)

Em resumo: a práxis surge em decorrência do trabalho desenvolvido pelos homens, na tentativa de criarem melhores condições de vida. Em tal processo, não só a natureza externa é modificada. Também a natureza interna passa por transformações que, ainda de acordo com a perspectiva defendida por Adorno e Horkheimer, trazem sempre a marca da renúncia e, por isso, da não-liberdade, mesmo quando isso já não se faz mais necessário. 
No mundo moderno, a práxis, originária do trabalho, já poderia ter sido abolida, mas, antes disso, o que se vê é que ela se direciona no sentido de perpetuar as condições existentes. Ao se submeter à aparelhagem econômica, colocando-se a serviço do capital, a práxis ratifica o estado de barbárie. À medida que se afasta da reflexão, representa uma manifestação do que foi denominado, por Horkheimer e Adorno, "ativismo de vistas curtas" (1973, p. 130). Diante do caráter instrumental e utilitário deste ativismo, o espaço para que a reflexão ocorra torna-se limitado.

A reflexão (o pensamento) exige a adoção de uma postura que torne possível elaborar questionamentos que se refiram ao que está dado. Tal postura - que traz em si um "potencial esclarecedor" (ADORNo, 1995b, p. 132) - requer, inclusive, a concessão de espaço para o surgimento de dúvidas. Mas a capacidade de elaborar questionamentos está se atrofiando, limitada por um modelo de ciência que se centra na exigência do sempreigual, nos procedimentos fechados de pesquisa. Para Adorno, é essa racionalidade do sempre-igual que conduz, em um sentido amplo, à perda da capacidade de desenvolverem-se experiências.

Quando se exige das ciências sociais que essa submeta seu objeto às técnicas de investigação fixas, que se adapte a estruturas previamente estabelecidas - e, por isso mesmo, que engessam as relações que se desenvolvem tanto entre sujeito e objeto como entre teoria e práxis -, a possibilidade de transformação fica reduzida. A ciência que se constitui de acordo com esses parâmetros atua no sentido de favorecer a aceitação (e a reafirmação) das condições de vida existentes, impossibilitando a emergência de momentos em que a recusa, a confrontação em relação a essas mesmas condições, seja realizada.

Finalizando, cabe ressaltar, mais uma vez, que esse movimento que tende, em última instância, à conformação, à resignação e que é assumido pelas ciências sociais que se atrelam, de maneira exclusiva, ao modelo da investigação social empírica - não se restringe apenas ao âmbito da ciência. Nele encontra-se o modo de operar da sociedade administrada, em que a preocupação com a eficácia, com o efeito e com o resultado sobrepõe-se à preocupação com as possibilidades de desenvolvimento da capacidade de reconhecimento e compreensão do processo de construção das relações sociais. E assim o progresso, vinculado a essa forma determinada de sociedade, mostra seu elemento autodestrutivo, a sua face regressiva. Adorno e Horkheimer foram contundentes ao afirmarem a necessidade de se pensar esse aspecto: 
Se o esclarecimento não acolhe dentro de si a reflexão sobre esse elemento regressivo, ele está selando o seu próprio destino. Abandonando a seus inimigos a reflexão sobre o elemento destrutivo do progresso, o pensamento cegamente pragmatizado perde seu caráter superador e, por isso, também sua relação com a verdade. (1984,p. 13)

Esse parece constituir o grande desafio da ciência: recuperar, de maneira efetiva, o potencial emancipador do esclarecimento. Tal tarefa adquire proporções mais amplas - e difíceis de serem suplantadas - em um mundo onde o pensamento, tal como as coisas, converteu-se em elemento de troca; um mundo em que fica evidente que a primazia e a fetichização da técnica não se desvinculam da constituição de homens tecnológicos; um mundo em que a reflexão e o desenvolvimento de experiências formativas - bases de todo o trajeto que conduz à autonomia - encontram-se, cada vez mais, obstados.

\section{ABSTRACT}

The objective of this article is to present some of the elements, which enable a reflection about the process of producing knowledge and its relation with social investigation, centralized in the adoption of empirical procedures. The main basis of reference is the Teoria Crítica da Sociedade (Critical Theory of the Society) - with a special emphasis in the ideas supported by T. Adorno and M. Horkheimer. The aim is to point out aspects, which express the development of rationalism, the interrelationship between enlightening and myth, and their consequent implications.

Key words: knowledge, social empirical investigation, critical theory.

\section{NOTAS}

1. Vale ressaltar, contudo, que Adorno, pautado por "categorias da teoria críticodialética", afirma que a sociedade também é capitalismo, em função das relações de produção que nela se processam. Uma discussão mais aprofundada, a esse respeito, pode ser encontrada no texto Sociedade industrial ou capitalismo tardio? (1986).

2. Cabe sublinhar, inclusive, que assumir a postura contrária, ou seja, negar a importância que os procedimentos empíricos têm (e tiveram) para as ciências, em geral, também representa um engano. 
3. É necessário destacar que essa mesma compreensão apresenta-se, na perspectiva adotada pelos autores citados, na análise da relação estabelecida entre teoria e práxis. A esse respeito, consultar o texto Notas marginais sobre teoria e práxis (1995).

\section{REFERÊNCIAS}

Adorno, T. Sociedade industrial ou capitalismo tardio? In: CoHn, G. Theodor W. Adorno. São Paulo: Ática, 1986, p. 62-75. Col. Grandes Cientistas Sociais.

Lacunas. In: Mínima morália. Tradução de Luiz Eduardo Bicca. 1. ed. São Paulo: Ática, 1992, p. 69-70.

. Sobre sujeito e objeto. In: Palavras e sinais - modelos críticos 2 . Tradução de Maria Helena Ruschel. 1. ed. Petrópolis, RJ: Vozes, 1995a, p. 181-201.

Notas marginais sobre teoria e práxis. In: Palavras e sinais - modelos críticos 2. Tradução de Maria Helena Ruschel. 1. ed. Petrópolis, RJ: Vozes, 1995a, p. 202-229.

Educação após Auschwitz. In: Educação e emancipação. Tradução de Wolfgang Leo Maar. 1. ed. São Paulo: Paz e Terra, 1995b, p. 169-186.

Adorno, T.; Horkheimer, M. Prefácio. In: Dialética do esclarecimento: fragmentos filosóficos. Tradução de Guido Antônio de Almeida. 2. ed. São Paulo: Jorge Zahar Ed., 1986, p. 11-17.

O conceito de esclarecimento. In: Dialética do esclarecimento: fragmentos filosóficos. Tradução de Guido Antônio de Almeida. 2. ed. Rio de Janeiro: Jorge Zahar Ed., 1986, p. 19-53.

O pensamento. In: Dialética do esclarecimento: fragmentos filosóficos. Tradução de Guido Antônio de Almeida. 2. ed. Rio de Janeiro: Jorge Zahar Ed., 1986, p. 228.

Sociologia e investigação social empírica. In: Temas básicos de sociologia. Tradução de Álvaro Cabral. 1. ed. São Paulo: Cultrix/USP, 1973, p. 120-131. 